\title{
Sexual dimorphism, population dynamics and some aspects of life history of Echiniscus mauccii (Tardigrada; Heterotardigrada)
}

\author{
Colleen R. MITCHELL* and Frank A. ROMANO III
}

Department of Biology, Jacksonville State University, 700 Pelham Road North, Jacksonville, Alabama 36265-1602, U.S.A.

*e-mail corresponding author: CRMitchell80@hotmail.com

\begin{abstract}
A fifteen month study (December 2002 though February 2004) of a meiofaunal community living in moss and lichen from a Pecan tree on the campus of Jacksonville State University reports 9,791 microinvertebrates. Echiniscus mauccii was the most prevalent tardigrade species (1,329 specimens) and was chosen to determine population dynamics and some aspects of their life histories. The average length of all the specimens (adults, juveniles, males, and females) for each month was determined. A plot of all E. mauccii specimens was used to determine the following life stages of this species; juvenile, pre-reproductive, and reproductive. The studied population exhibited relatively constant population size and juvenile recruitment occurred year round with no increased reproduction during a season of the year. Thus, E. mauccii is an opportunistic breeder. Males of this species were found for the first time on a Laurasian land mass and females were found to be significantly larger than males. A protected Fisher's LSD test revealed a significant negative relationship between average adult length and the number of adults collected per month, but not between adult and juvenile lengths. As the population became more dense the average adult size decreased suggesting competition between at least the adults. Echiniscus mauccii is a sexually dimorphic animal that is iteroparous, breeds whenever conditions are appropriate, has a relatively constant population size, produces a small number of large eggs, and exhibits competition between adults. Thus, E. mauccii exhibits classic $K$-selected traits.
\end{abstract}

Key words: Heterotardigrade, Echiniscus mauccii, population dynamics, life history aspects, sexual dimorphism

\section{INTRODUCTION}

Many studies have been concerned with tardigrade morphology, taxonomy, and distribution; however, few are concerned with population dynamics and life histories. Higgins (1959) analyzed a population of Macrobiotus islandicus Richters, 1904 (a limno-terrestrial eutardigrade) in Boulder Canyon, Colorado. This study followed the molting process through all instars (defined as periods after ecdysis and do not reflect the adult status), and is the first known analysis of tardigrades. Each individual animal's body length was measured to determine life stages. The number of individuals plotted against body length indicated that there were presumably seven instars or six probable ecdyses (2 juvenile and 4 adult). Adults formed eggs after the third instar and all subsequent instars contained eggs. Schuster et al. (1977) analyzed a population of Dactylobiotus grandipes (an aquatic eutardigrade), at Pope Beach, Lake Tahoe, California over a twelve month period. Body lengths of the animals in this study ranged from $175 \mu \mathrm{m}$ to about $1044 \mu \mathrm{m}$. The number of instars of this species was not clearly determined but 5 periods of ecdysis were probable (two juvenile and three adult). This population was seasonally reproductive (spring) and was essentially dormant for six months during winter. Some adults were able to survive to a second year.
A significant life history study was performed by Suzuki (2003) on a lab culture of Milnesium tardigradum Doyère, 1840 (a limno-terrestrial eutardigrade). Many aspects of the tardigrade's life cycle were observed while the animals were still living in vitro. All reproduction in this population was parthenogenetic. The longest life span of an individual in this study was 58 days. In one study, it seems that terrestrial tardigrades need periods of being in the tun to aid in their longevity and survival (Suzuki 2003). A similar laboratory study was done by Altiero et al. (2006) on Macrobiotus richtersi Murray, 1911 (a limno-terrestrial eutardigrade) specifically looking for aspects of life history such as life span, clutch sizes, and age at different ovipositions. In this study two clones (due to apomictic parthenogenesis) were taken through a few generations in a laboratory setting. The two clones had many similarities such as life span, total number of ovipositions per life span, and age at first oviposition. Some of the significant differences in the two clones were the mean clutch size, the mean number of eggs laid by each female per life span, and embryonic development length.

This study analyzed aspects of the life history and population dynamics of a moss and lichens dwelling heterotardigrade Echiniscus mauccii Ramazzotti, 1956, using a population living on a pecan tree. 

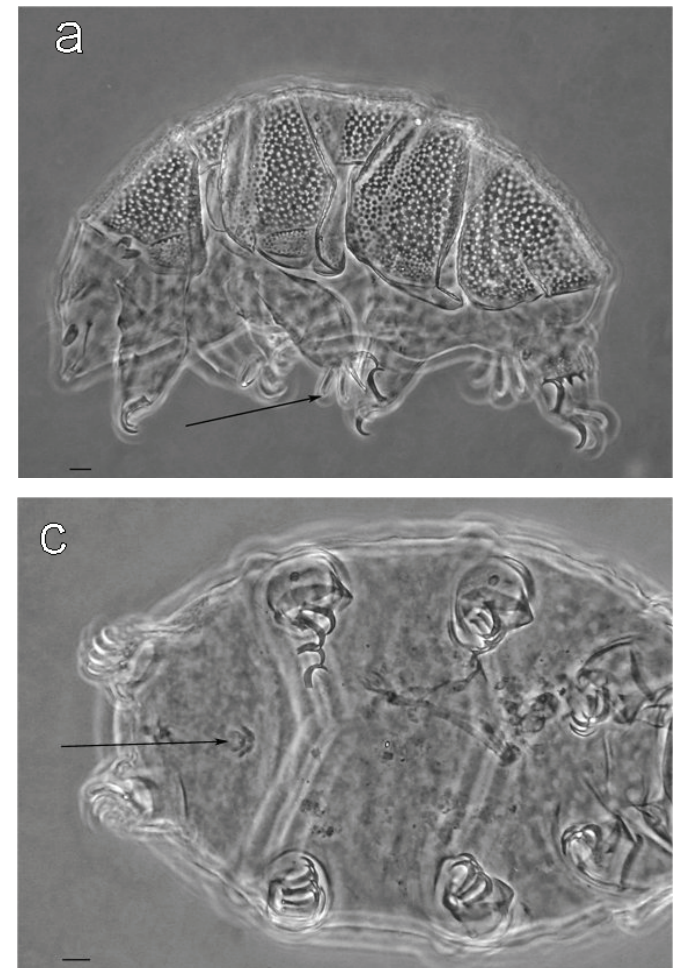
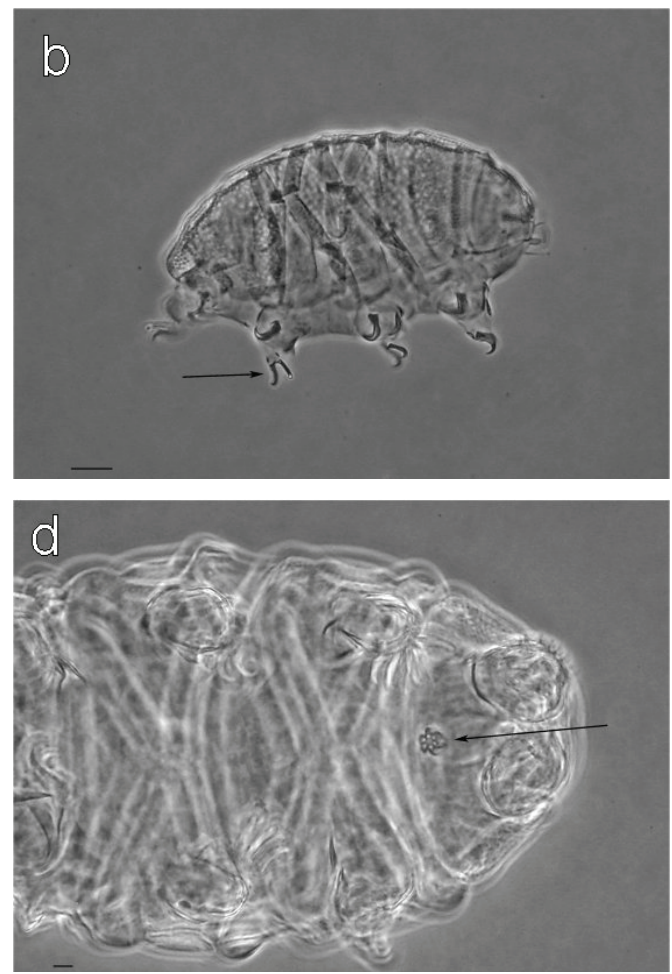

Fig. 1. Echiniscus mauccii (Hoyer's medium; phase contrast). a: Adult specimen (arrow indicates the 4 claws). b: Juvenile specimen (arrow indicates the 2 claws). c: Male adult specimen (arrow indicates male gonopore). d: Female adult specimen (arrow indicates female gonopore). Scale bars: a-d $=10 \mu \mathrm{m}$.

\section{METHODS}

Moss and lichen samples were collected from a pecan tree (Carya illinoensis (Wangenh.) K. Koch, 1969) located on the Jacksonville State University Campus, Jacksonville, Alabama, U.S.A. Three $25 \mathrm{~cm}^{2}$ samples were collected monthly for fifteen months (December 2002 through February 2004). Samples were collected from the tree trunk and the bases of major limbs between $3 \mathrm{~m}$ and $6 \mathrm{~m}$ above the ground in all seasons of the year, i.e., spring, summer, fall, and winter). In the lab dried samples were soaked for twenty-four hours in water using the 'bear trap' methodology of Nelson (1975). Decanted water from the samples was run through three sieves $(250 \mu \mathrm{m}, 150 \mu \mathrm{m}, 45 \mu \mathrm{m})$. The sample from the $45 \mu \mathrm{m}$ sieve was collected into a sample bottle. Boiling $70 \%$ isopropyl alcohol was added to the sample bottle to kill and preserve the specimens (40\% isopropyl alcohol final dilution). The mosses and lichens were then dehydrated and stored in the collection bags.

Processing of the sample consists of counting and removing all tardigrades and both free eggs and exuvia with eggs from the sample and individually mounting adults on slides in Hoyer's medium, while the eggs were mounted with up to five free eggs per slide. The slides were made permanent by ringing the cover slip with epoxy paint.

Once mounted each tardigrade length was measured (to the nearest $\mu \mathrm{m}$ using a $10 \times$ objective) from the tip of the first cephalic segment to between the fourth pair of legs on the fourth trunk segment. Data were collected and analyzed using Image-Pro Plus software ${ }^{\circledR}$. Tardigrades were identified to species, using Ramazzotti \& Mauccii (1983) and current literature, and the most abundant species, E. mauccii was the focus of the life history portion and population dynamics of this study. The adults, juveniles (two-clawed), and eggs were counted and measured to determine seasonal patterns of each stage of the life cycle. Each monthly collection of E. mauccii was separated into groups (juveniles, adults, males, females) and the average length of each group was calculated and reported. Data were analyzed following the methodology of Steel \& Torrie (1980). A plot of all of the E. mauccii specimens was constructed to determine the life stages of this species. A multiple comparison test was run on the E. mauccii data using a protected Fisher's LSD test. The male and female lengths were compared with Student's $t$-Test.

\section{RESULTS}

This study found 9,791 microinvertebrates (rotifers, nematodes, harpactocopepods, collembola, and mites) of which there were 2,131 tardigrade specimens and 582 tardigrade eggs were isolated. Echiniscus manccii (Fig. 1 and Tab. 1) was the most abundant species found in this study represented by 1,329 specimens (107 juveniles and 1,222 adults). 


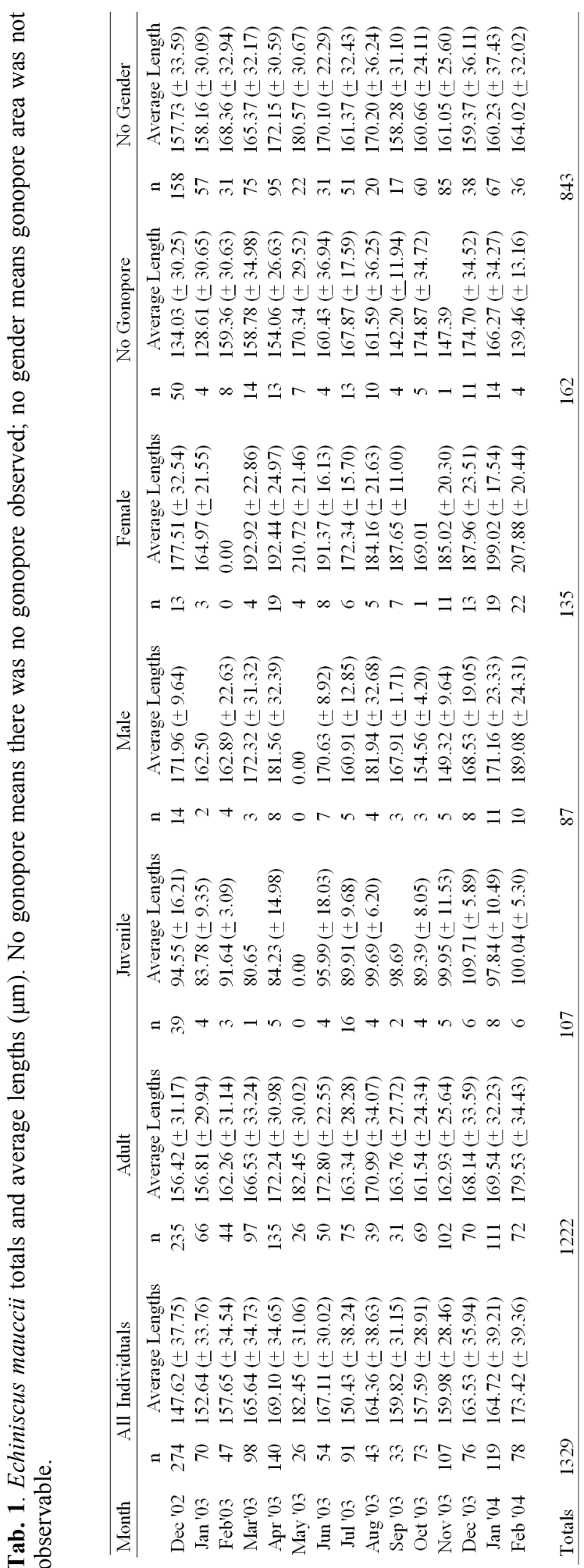


Tab. 2. Multiple comparison of mean size by month for Echiniscus mauccii. Numbers above the diagonal line are for all individuals and are the absolute differences between the two means (protected Fisher's LSD $=3.66$ ). Below the diagonal line are adults only (protected Fisher's LSD $=1.69$ ). ${ }^{*}=\alpha=0.01 . \mathrm{NS}=$ non-significant.

\begin{tabular}{|c|c|c|c|c|c|c|c|c|c|c|c|c|c|c|c|}
\hline Month & Dec '02 & Jan '03 & Feb '03 & Mar '03 & Apr '03 & May '03 & Jun '03 & Jul '03 & Aug '03 & Sep '03 & Oct '03 & Nov '03 & Dec '03 & Jan '04 & Feb '04 \\
\hline Dec '02 & & NS & * & * & * & * & * & $*$ & $*$ & $*$ & $*$ & $*$ & $*$ & $*$ & * \\
\hline Jan '03 & $*$ & & $*$ & $*$ & $*$ & $*$ & $*$ & $*$ & $*$ & $*$ & $*$ & $*$ & * & $*$ & $*$ \\
\hline Feb '03 & $*$ & $*$ & & $*$ & $*$ & $*$ & $*$ & NS & * & NS & NS & NS & $*$ & $*$ & $*$ \\
\hline Mar '03 & $*$ & * & * & & $*$ & * & $*$ & $*$ & $*$ & $*$ & $*$ & $*$ & NS & $*$ & * \\
\hline Apr '03 & $*$ & $*$ & $*$ & NS & & $*$ & NS & $*$ & NS & $*$ & $*$ & $*$ & $*$ & NS & $*$ \\
\hline May '03 & $*$ & $*$ & $*$ & $*$ & $*$ & & $*$ & $*$ & $*$ & $*$ & $*$ & $*$ & $*$ & $*$ & $*$ \\
\hline Jun '03 & $*$ & $*$ & $*$ & NS & NS & $*$ & 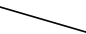 & $*$ & $*$ & $*$ & $*$ & $*$ & $*$ & $*$ & $*$ \\
\hline Jul '03 & NS & NS & $*$ & $*$ & $*$ & $*$ & $*$ & & $*$ & NS & $*$ & NS & $*$ & $*$ & $*$ \\
\hline Aug '03 & $*$ & $*$ & $*$ & NS & $*$ & $*$ & NS & $*$ & 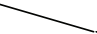 & $*$ & * & $*$ & $*$ & NS & $*$ \\
\hline Sep '03 & $*$ & $*$ & NS & $*$ & $*$ & $*$ & $*$ & $*$ & $*$ & & $*$ & NS & * & $*$ & $*$ \\
\hline Oct ' 03 & $*$ & $*$ & NS & $*$ & $*$ & $*$ & $*$ & $*$ & $*$ & NS & & NS & $*$ & $*$ & $*$ \\
\hline Nov '03 & * & * & NS & $*$ & * & * & $*$ & $*$ & * & NS & NS & T. & * & * & $*$ \\
\hline Dec '03 & $*$ & * & $*$ & NS & $*$ & * & NS & $*$ & NS & $*$ & $*$ & NS & & * & $*$ \\
\hline Jan '04 & $*$ & * & $*$ & NS & $*$ & $*$ & NS & $*$ & NS & $*$ & $*$ & $*$ & NS & & $*$ \\
\hline Feb '04 & $*$ & $*$ & $*$ & $*$ & $*$ & $*$ & $*$ & $*$ & $*$ & $*$ & $*$ & $*$ & $*$ & $*$ & \\
\hline
\end{tabular}

Adults were separated into two groups, those where the area of the gonopore was visible $(\mathrm{n}=384)$ or not visible $(\mathrm{n}=843)$. Those with a visible gonopore area were separated into males $(\mathrm{n}=87)$, females $(\mathrm{n}=135)$, and those without gonopores $(\mathrm{n}=162)$ Adults averaged $165.84(+31.09) \mu \mathrm{m}$ in length, females averaged 192.42 $(+23.95) \mu \mathrm{m}$ in length, males averaged $170.66(+23.39)$ $\mu \mathrm{m}$ in length and juveniles averaged $94.56(+13.39) \mu \mathrm{m}$ in length. Two exuviae with eggs were collected during this study. The first exuvium (170 $\mu \mathrm{m}$ in length) contained a single egg with a width of $51.9 \mu \mathrm{m}$. The second exuvium $(234 \mu \mathrm{m}$ in length) contained three eggs $(77.66,82.58,84.69 \mu \mathrm{m})$ that had an average width of $81.64 \mu \mathrm{m}$. It was noted that females were on average larger than males (Tab. 1) Females were found to be significantly larger than the males $(t=-6.73, \mathrm{df}=199, p$ $<0.001$ ). In table 1 juveniles are those 'larval' forms with only 2 claws per leg. The no gonopore individuals are those with 4 claws per leg and have no gonopore. These would be considered to be pre-reproductives. The no gender individuals are adults (4 claws per leg) but because of mounting, the area of the gonopore was not visible.

The average body length during this study varied between $156.42(+32.7) \mu \mathrm{m}$ (December '02) and 182.45 (+31.02) $\mu \mathrm{m}$ (May '03) in adults, between $80.65 \mu \mathrm{m}$ (March '03) and $109.70(+5.43) \mu \mathrm{m}$ (December '03) in juveniles, between $164.97(+21.55) \mu \mathrm{m}$ (January '03) and 210.72(+21.46) $\mu \mathrm{m}$ (May '03) in females, and between $149.32(+9.64) \mu \mathrm{m}$ (November '03) and 189.08 $(+24.31) \mu \mathrm{m}$ (February '04) in males. Comparing the mean lengths of the E. mauccii adults and juveniles by month showed the mean length fluctuated little during the study (Tab. 1). Adult means only varied by $26 \mu \mathrm{m}$ (14\%) and juvenile means varied by $29 \mu \mathrm{m}(26 \%)$. To determine which months were significantly different, a protected Fisher's LSD test was performed (Tab. 2). There are only a few months that are not statistically different when testing for either adults or all individuals. There is no pattern to either the months that are significantly different or not significantly different. In addi- tion, there is no pattern when comparing late fall and winter in different years. A regression between the average lengths of an adult versus the number of individuals in that month revealed a statistically significant negative relationship $\left(r^{2}=-0.468, p=0.0049\right)$.

Based on the 491 individuals (adults with the area of the gonopore visible and juveniles) three major life stages were identified for E. mauccii; juvenile, prereproductive, and reproductive (Fig. 2). The presence of juvenile characteristics as well as adult and sexually dimorphic characteristics was used to separate these life stages (Fig. 1 and Tab. 1). Juveniles have only two claws per leg and no gonopore or anus and have a length range from 65 to $125 \mu \mathrm{m}$. Pre-reproductive adults have four claws per leg, an adult characteristic, no gonopore and have a length range from 85 to $150 \mu \mathrm{m}$. Reproductive adults have four claws per leg and a gonopore (male or female) and have a length range from 135 to $265 \mu \mathrm{m}$; males range in length from 135 to 220 $\mu \mathrm{m}$ and females from 155 to $265 \mu \mathrm{m}$. Males, females, and juveniles were found in virtually all months (14 out of 15 months), while individuals without gonopores were found in all months of the study. The months with no males, females or juveniles were months of low numbers (February and May '03). These months also had many individuals in which the gender could not be determined because of their position while mounting (33 and 15 respectively).

\section{DISCUSSION}

This study reports on sexual dimorphism, population dynamics and the some aspects of the life history of Echiniscus mauccii. This species was chosen because of the high number of individuals found in the samples taken. Echiniscus mauccii is known only from some localities of North America. One significant discovery is that this is the first reported incidence of Echiniscus males in a Laurasian land mass. Echiniscus is a cosmopolitan genus rich in species, most of them without males. All of the other known cases of male Echiniscus were found on the present continents that were part of 


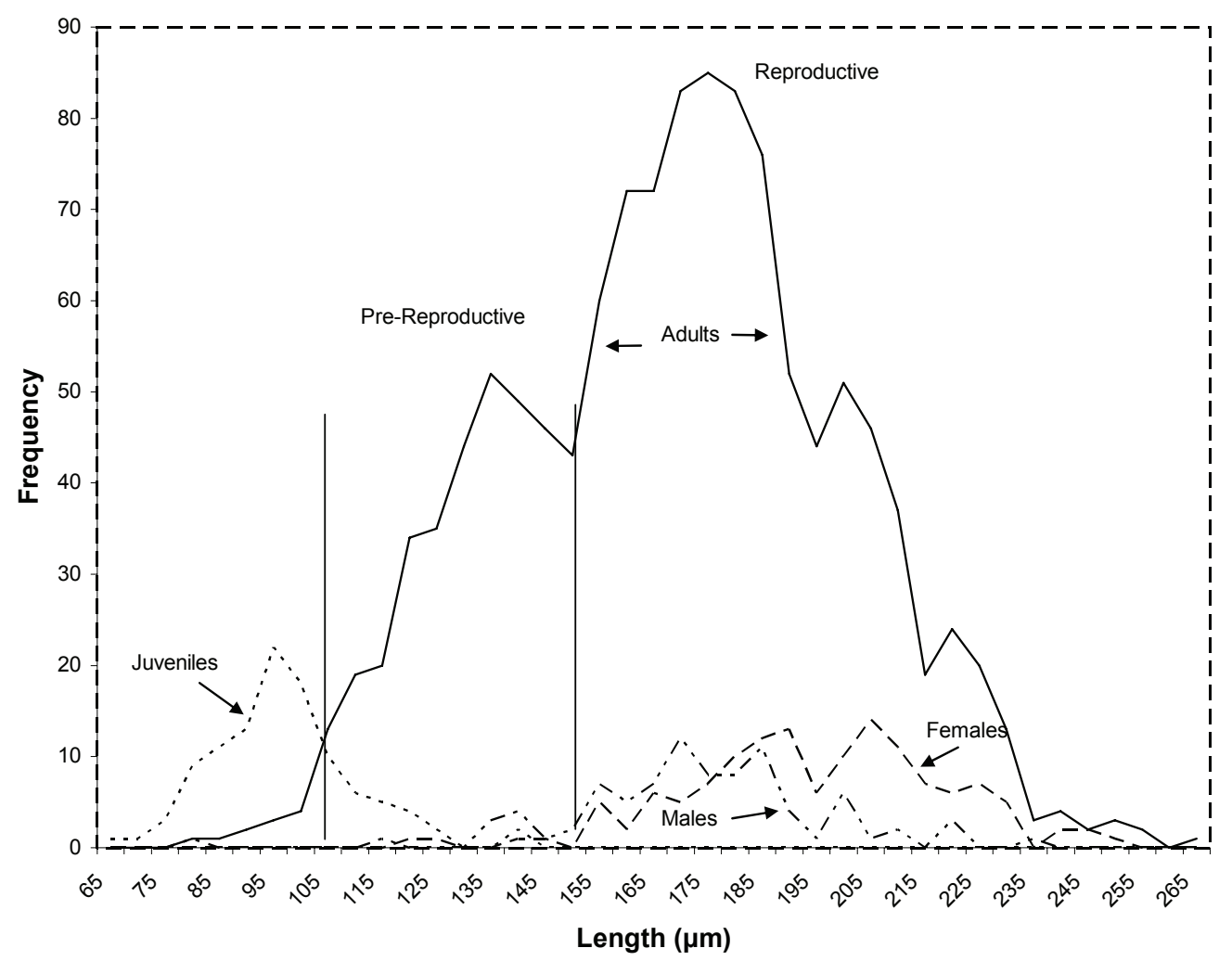

… Juvenile

Fig. 2. Plot of the life history stages of Echiniscus manccii.

Gondwana (Miller et al. 1999). Excluding the very remote possibility of origin from a unisexual ancestor, there are two significant hypotheses on the origin of the bisexual species E. mauccii. 1. Echiniscus and its sexually dimorphic evolutionary lines, including that leading to E. mauccii, originated before the splitting of Gondwana and Laurasia and subsequently they developed mostly in Gondwana. 2. Echiniscus and its bisexual evolutionary lines originated in Gondwana after this splitting, but before the subsequent splitting which separated the current continents and sub-continents. In the latter case, the various unisexual species currently colonizing Laurasia originated from single parthenogenetic individuals from Gondwana favored in the passive dispersal because of their ability to colonize a new territory with only one individual, whereas E. mauccii or its ancestor passed from South to North America during the Great American Exchange, or previous connections, or thanks to a rare case of wide passive dispersal involving specimens of both sexes directed to the same territory. In the first hypothesis, we should explain why only one sexually dimorphic species of Echiniscus could have originated in Laurasia, versus the many sexually dimorphic species that originated in Gondwana. In the latter case, we must explain the absence of Echiniscus with males in South America, but in reality we have little information on sex ratio on all the species of that subcontinent. We should remember that, according to Ramazzotti \& Maucci (1983), i.e. about 25 years ago, among the species of all the family of Echiniscidae of the entire world, only two species of Pseudechiniscus were known to have males. Currently there are several species with males worldwide (Echiniscus apart) belonging to several genera. If in the future, the sex ratio of Echiniscus will be considered with more attention, probably we could find an answer to this question.

In further analysis of the sexual dimorphism, it was found that males are significantly smaller than the females. This agrees with Miller et al. (1999) that discovered similar sexual dimorphism in three other Echiniscus species. Females, distinguished by their gonopore, are larger than males and produce a few relatively large eggs. A regression of average size against the number of individuals collected in a month produced a significant negative relationship. Thus, when many adults are present they are smaller in size.

Each life stage of E. mauccii is represented in figure 2. In this figure (a plot of Tab. 1) the juvenile stage is represented by the 2 claws per leg with no gonopore; the pre-reproductive stage is represented by individuals with 4 claws per leg and no gonopores; the reproductive stage is represented by all adults (male and female) with 
gonopore. Realize that a portion of the adults (4 claws per leg) were mounted so that the gonopore area was visible but it was not there; this is the no gonopore group. Since E. mauccii has a thickened cuticle it was impossible to see inside and look at the gonad area. It was impossible to tell whether these animals were prereproductive or reproductives. Realize that their size range overlaps both. It is important to note here that there are many individuals in this study that were not in the optimal position to determine the status of the gonopore and are included in table 1 but not in figure 2 . The pre-reproductive life-stage is characterized by adults having four claws per leg and no gonopore. The line that separates pre-reproductives and reproductives in figure 2 was placed at this point since most of them are shorter than most males and females. Obviously individuals mature at different rates, thus, there are a few small males and females mixed within this lifestage size class, but most of these individuals do not have gonopores and are truly pre-reproductives. The reproductive life-stage is characterized by adults having both four claws per leg and gonopores (male or female).

It was found that throughout the study there was only one month (May) where juveniles, males, and females were not found which suggests that sexual reproduction goes on during the entire year (Tab. 1). If reproduction goes on during the entire year and there is no seasonality, this suggests that these animals are opportunistic breeders, in that they breed anytime the conditions are appropriate for the individuals and can do this at any point during the year. There is evidence that females can produce eggs at $170 \mu \mathrm{m}$ and $234 \mu \mathrm{m}$ since exuvia were found of these sizes. Thus, adults most likely are iteroparous confirming the suggestion that all non-marine heterotardigrades are iteroparous (Rebecchi et al. 2000).

Pianka (1970) suggested that species that are colonizers are semelparous, produce a large number of small eggs, exhibit rapid population growth, have a variable or non-equilibrium population size, have the ability to withstand variable or unpredictable climatic conditions, and often lack intraspecific and interspecific competition. These organisms were termed ' $r$-selected' suggesting their ability to reproduce very quickly, maximizing their reproductive potential $(r)$. In contrast, those species that survive well under conditions close to the carrying capacity of their environment $(\mathrm{K})$ are iteroparous, produce a small number of large eggs, exhibit relatively stable populations, live in more stable or predictable climates, and usually exhibit keen intraspecific and interspecific competition. These organisms were termed 'K-selected'. Echiniscus mauccii has classic K-selected traits, in that they produce a small number of large eggs, are iteroparous, have a relatively constant population size, and exhibit intraspecific competition, at least between adults.

\section{ACKNOWLEDGMENTS}

The authors express their gratitude to Drs. Clark Beasley (McMurray University, Abilene, TX), William Miller (Chestnut Hill College, Philadelphia, PA), George Cline (Jacksonville State University, Jacksonville, AL), Lorena Rebecchi (University of Modena and Reggio Emilia, Modena, Italy), and Roberto Guidetti (University of Modena and Reggio Emilia, Modena, Italy) for their help with this manuscript.

\section{REFERENCES}

Altiero, T., L. Rebecchi \& R. Bertolani. 2006. Phenotypic life history variations in two clones of Macrobiotus richtersi (Eutardigrada, Macrobiotidae). Hydrobiologia, 558: 3340.

Higgins, R.P. 1959. Life history of Macrobiotus islandicus Richters with notes on other tardigrades from Colorado. Trans. Am. Microsc. Soc., 78: 137-154.

Miller, W.R., S.K. Claxton \& H.F. Heatwole. 1999. Tardigrades of the Australian Antarctic Territories: Males in the genus Echiniscus (Tardigrada: Heterotardigrada). Zool. Anz., 238: 303-309.

Nelson, D.R. 1975. Ecological distribution of tardigrades on Roan Mountain, Tennessee-North Carolina. Mem. Ist. ital. Idrobiol., 32: 225-276.

Pianka, E.R. 1970. On r and K selection. Am. Nat., 102: 592597.

Ramazzotti, G. \& W. Maucci. 1983. Il Phylum Tardigrada. Terza edizione riveduta e aggiornata. Mem. Ist. ital. Idrobiol., 41: 1-1014.

Rebecchi, L., A. Guidi \& R. Bertolani. Maturative pattern of the ovotestis in two hermaphrodite species of eutardigrades. Invertebr. Reprod. Dev., 37: 25-34.

Schuster, R.O., E.C. Toftner \& A.A. Grigarick. 1977. Tardigrada of Pope Beach, Lake Tahoe, California. Wassman J. Biol., 35: 115-136.

Steel, R.G.D. \& J.H. Torrie. 1980. Principles and Procedures of Statistics: A Biometrical Approach. McGraw-Hill Book Co., New York: 633 pp.

Suzuki, A.C. 2003. Life history of Milnesium tardigradum Doyère (Tardigrada) under a rearing environment. Zool. Sci., 20: 49-57. 